\title{
Estudo retrospectivo de 66 casos de urolitíase obstrutiva em ovinos ${ }^{1}$
}

\author{
Janaina Azevedo Guimarães ${ }^{2 *}$, Carla Lopes de Mendonça², Eduardo Levi de Sousa \\ Guaraná2 ${ }^{2}$ Alexandre Cruz Dantas ${ }^{2}$, Nivaldo de Azevêdo Costa² ${ }^{2}$ Antônio Carlos \\ Lopes Câmara ${ }^{3}$, Carlinda Campelo Farias ${ }^{4}$ e José Augusto Bastos Afonso ${ }^{2}$
}

\begin{abstract}
Guimarães J.A., Mendonça C.L., Guaraná E.L.S., Dantas A.C., Costa N.A., Câmara A.C.L., Farias C.C. \& Afonso J.A.B. 2012. [Obstrutive retrospective study of 66 cases of urolithiasis in sheep.] Estudo retrospectivo da urolitíase obstrutiva em ovinos: análise de 66 casos. Pesquisa Veterinária Brasileira 32(9):824-830. Clínica de Bovinos, Campus Garanhuns, Universidade Federal Rural de Pernambuco, Av. Bom Pastor s/n, Cx. Postal 152, Garanhuns, PE 55292-270,Brazil. E-mail: janainagvet@gmail.com

The aim was to conduct a retrospective study of the main epidemiological, clinical, pathological and laboratory findings from sheep suffering from obstructive urolithiasis, in the Agreste region of Pernambuco, Brazil. Thus, 66 medical records of non-castrated male sheep with age from 2 months and 5 years were analyzed. Most cases $(79.63 \%)$ occurred during the rainy season. Most sheep were raised intensively (87.88\%) and all were fed with concentrated ration. Main clinical signs were manifestation of pain, congestion of the mucosae, hyperthermia, and increased abdominal tension associated with urinary tract obstruction. Half of the animals showed total obstruction of the urethra, $69.7 \%$ of which died, whilst in cases of partial obstruction only $30.3 \%$ died. Laboratorial exams revealed neutrophilia and regenerative left turn, hyperfibrinogenemia, and azotemia. Urinalysis showed hematuria in $89.29 \%$ of the cases, and acidic $\mathrm{pH}$ in $46.43 \%$. Erythrocytes, leukocytes, cell desquamation of urethral epithelium, and crystals of amorphous urate predominated in the examination of the sediment. Most frequent gross findings were pyelonephritis (61.54\% of cases) and hydronephrosis (50\%). In the ureter, ureteritis and hydroureter was observed. The bladder showed diffuse hemorrhagic cystitis (50\%) and uroliths (57.69\%). In the urethra, uroliths (61.54\%) and diffuse hemorrhagic urethritis (57.69\%) was found. The uroliths were composed mainly by hydrated calcium oxalate. It is concluded that in the Agreste region of Pernambuco, urolithiasis is an important disease of sheep with high mortality, associated with the ingestion of large amounts of concentrates and mineral supplements.
\end{abstract}

INDEX TERMS: Urinary tract, urolithiasis, urea, creatinine, calcium, oxalate, small ruminants.

RESUMO.- Objetivou-se realizar um estudo retrospectivo dos principais achados epidemiológicos, clínicos, patológicos e laboratoriais de ovinos acometidos por urolitíase obstrutiva, atendidos na Clínica de Bovinos, Campus Gara-

\footnotetext{
${ }^{1}$ Recebido em 10 de dezembro de 2011.

Aceito para publicação em 4 de abril de 2012.

${ }^{2}$ Clínica de Bovinos, Universidade Federal Rural de Pernambuco, Campus de Garanhuns, Avenida Bom Pastor s/n, Bairro Mundaú, Caixa Postal 152, Garanhuns, PE 55292-270, Brasil. *Autor para correspondência: janainagvet@gmail.com

${ }^{3}$ Universidade Federal Rural do Semiárido, BR 110 Km 47, Mossoró, RN 59625-900, Brasil.

${ }^{4}$ Laboratório de Mineralogia, Departamento de Geologia, Universidade Federal de Pernambuco, Av. Moraes Rego 1235, Cidade Universitária, Recife, PE 50670-901, Brasil
}

nhuns/ UFRPE. Para isso, foram analisadas 66 fichas clínicas de ovinos, todos machos não castrados, com idade entre dois meses e cinco anos. A maioria dos casos $(79,63 \%)$ ocorreu na época chuvosa. A maioria dos animais $(87,88 \%)$ era criada intensivamente e todos eram alimentados com concentrados. Os sinais clínicos mais importantes foram as manifestações de dor, congestão de mucosas, hipertermia e aumento da tensão abdominal associados a obstrução do trato urinário. Metade dos animais apresentou obstrução total da uretra. Destes, $69,70 \%$ morreram, enquanto nos casos de obstrução parcial, 30,30\% morreram. Nos exames laboratoriais verificou-se neutrofilia e desvio à esquerda regenerativo, hiperfibrinogenemia e azotemia. Na urinálise constatou-se hematúria em $89,29 \%$ dos casos e pH ácido em $46,43 \%$. Na sedimentoscopia predominaram hemácias, 
leucócitos, células de descamação do epitélio uretral e cristais de urato amorfo. Os achados necroscópicos renais mais frequentes foram pielonefrite $(61,54 \%$ dos casos $)$ e hidronefrose $(50 \%)$. Nos ureteres foram visualizados ureterite e hidroureter. Na bexiga foi mais evidente a cistite hemorrágica difusa (50\%) e a presença de urólitos $(57,69 \%)$. $\mathrm{Na}$ uretra observaram-se urólitos $(61,54 \%)$ e uretrite hemorrágica difusa $(57,69 \%)$. Quanto à composição dos urólitos predominaram os compostos por oxalato de cálcio hidratado. Conclui-se que no Agreste de Pernambuco a urolitiase é uma doença importante de ovinos, com alta letalidade, estando associada à alimentação rica em concentrados e sal mineral.

TERMOS DE INDEXAÇÃO: Trato urinário, urolitíase, uréia, creatinina, cálcio, oxalato, pequenos ruminantes.

\section{INTRODUÇÃO}

A intensificação da produção, aliada à comercialização de animais de alto valor genético, acarretou profundas alterações no manejo alimentar dos ovinos, desencadeando o aumento da ocorrência de doenças nutricionais e metabólicas (Ortolani 1996), entre as quais se destaca a urolitíase obstrutiva, considerada a enfermidade de maior importância do trato urinário de ruminantes, particularmente machos (Melendez et al. 2007).

A urolitíase é uma enfermidade que causa sérios prejuízos econômicos em pequenos ruminantes, estando relacionada à saída prematura dos animais da reprodução, gastos com tratamento, morte dos animais afetados e condenação da carcaça em abate emergencial. Em situações em que o principal componente da alimentação é o concentrado, 40 a $60 \%$ dos animais podem desenvolver este distúrbio e o índice de letalidade é elevado nos casos de obstrução total da uretra, principalmente quando resulta em ruptura desta ou da bexiga (Donecker \& Bellamy 1982, Radostits et al. 2007).

O quadro clínico pode variar dependendo da localização da obstrução e se esta é completa ou parcial. A maioria dos casos está associada à obstrução uretral, sendo frequentes as localizações, como o arco isquiático, a flexura sigmóide, a glande do pênis e o processo uretral. Um dos fatores considerado como complicador na resolução da enfermidade é a demora no atendimento clínico dos animais acometidos, refletindo nos índices de recuperação. Condições clínicas em que são observados sinais de edema extensivos na região do prepúcio, períneo e testículo, além da ausência de micção, retratam esta condição de gravidade e o maior risco de insucesso do tratamento (Bruère \& West 1993).

Este artigo teve por objetivo realizar um estudo retrospectivo dos principais achados epidemiológicos, clínicos e laboratoriais em ovinos acometidos com urolitíase obstrutiva, bem como, relatar os achados de necropsia e a composição química dos urólitos coletados.

\section{MATERIAL E MÉTODOS}

Foram analisadas as fichas clínicas de 66 ovinos, machos, com diagnóstico de urolitíase obstrutiva internos na Clínica de Bovinos, Campus Garanhuns da Universidade Federal Rural de Per- nambuco (CBG/UFRPE) no período de janeiro de 2001 a agosto de 2008. Para tal foram coletadas as informações epidemiológicas, clínicas, laboratoriais e anátomo-patológicas. Dentre os dados epidemiológicos resgatados estão a sazonalidade, a faixa etária, a raça, o sistema de criação, o tipo de manejo alimentar, o escore corporal e se o animal era castrado ou não e o número de mortes.

Os animais internos foram submetidos ao exame clínico seguindo as recomendações descritas por Pugh (2004). Dentre os exames laboratoriais analisados foram selecionados o hemograma, a determinação da proteína plasmática total (PPT), o fibrinogênio plasmático (FP) (Jain 1986), a urinálise (Garcia-Navarro 1996) e a determinação dos níveis séricos de uréia e creatinina, que foram determinados por meio de kits comerciais (Labtest Diagnóstica) e leitura efetuada em analisador bioquímico semi-automático (Labquest).

Para estudo dos dados anátomo-patológicos foram resgatados os laudos de necropsia onde foram observadas as informações referentes às lesões macroscópicas do trato urinário (Confer \& Panciera 1998).

Foi possível a coleta de 18 amostras de urólitos. Esta foi realizada mediante sondagem uretral ou por filtração do líquido vesical coletado no momento da necropsia. A análise da composição química dos cálculos urinários foi realizada utilizando a técnica da difração de Raios-X, descrita por Betejtin (1977).

\section{RESULTADOS}

A distribuição dos casos atendidos entre os anos de 2001 e 2008 foi: um, um, um, quatro, sete, 22, 20 e 10, respectivamente, perfazendo um total de 66 casos. Neste período observou-se um aumento gradual da ocorrência desta enfermidade nos ovinos internos, intensificando-se a partir do ano de 2004 , sendo que $79,63 \%$ dos casos ocorreram na estação chuvosa.

Todos os animais estudados eram machos não castrados das raças Santa Inês $(77,27 \%)$, Dorper $(21,21 \%)$ e Somalis $(1,52 \%)$ com idade variando de dois meses a cinco anos, dos quais $44,26 \%$ apresentavam idade igual ou inferior a seis meses, $14,45 \%$ entre sete meses e um ano e $40,99 \%$ acima de um ano de idade.

A criação intensiva representava $87,88 \%$ dos casos analisados e a alimentação a base de concentrado prevaleceu em todas as criações (Quadro 1). Dos animais que recebiam concentrado, $41,27 \%$, recebiam também uma mistura feita nas fazendas a base de soja, milho, aveia, cenoura e outros e 80,95\% também eram suplementados com sal mineral. Esta dieta refletiu-se bem no escore de condição corporal dos animais (ECC), que foi avaliado em escala de um a cinco, sendo observado que $7,81 \%$ dos animais estavam com

Quadro 1. Descrição da alimentação dos animais atendidos na CBG com quadro de urolitíase obstrutiva

\begin{tabular}{lcc}
\hline \multicolumn{1}{c}{ Alimentação } & Porcentagem & Porcentagem \\
\hline Concentrado à vontade + feno & 33,85 & \multirow{2}{*}{90,76} \\
Concentrado à vontade + feno + capim & 27,69 & \\
Concentrado à vontade + capim & 29,22 & \\
Volume de concentrado controlado + feno & 1,54 & 7,7 \\
Volume de concentrado controlado + feno & 3,08 & \\
$\quad+$ capim & & \\
Volume de concentrado controlado + capim & 3,08 & \\
Não recebe concentrado & 1,54 & 1,54 \\
TOTAL & $100 \%$ & $100 \%$
\end{tabular}


ECC dois, 25\% com ECC três, 48,44\% com ECC quatro e 18,75\% com ECC cinco.

Os principais achados clínicos estão descritos no Quadro 2. Das alterações laboratoriais encontradas, destacaram-se uma contagem leucocitária no limite superior, com neutrofilia e desvio à esquerda regenerativo, hiperfibrinogenemia e azotemia (Quadro 3). Enquanto os achados da urinálise estão nos Quadros 4 e 5.

0 índice de letalidade variou de acordo com o tipo de obstrução. Nos casos de obstrução total, 69,70\% dos animais vieram a óbito, enquanto nos casos de obstrução parcial este percentual foi de $30,30 \%$.

Quadro 2. Principais achados clínicos observados em ovinos com quadro de urolitíase obstrutiva atendidos na CBG, no período de janeiro de 2001 a agosto de 2008

\begin{tabular}{|c|c|c|c|c|}
\hline \multicolumn{2}{|l|}{ Parâmetros } & Achados & \multicolumn{2}{|c|}{$\begin{array}{c}\text { Número de animais } \\
\text { em } \%\end{array}$} \\
\hline \multirow[t]{2}{*}{ Micção } & \multicolumn{2}{|c|}{ Ausente } & & 50 \\
\hline & \multicolumn{2}{|c|}{ Em gotas } & & 50 \\
\hline \multirow[t]{2}{*}{ Frequência cardíaca } & \multicolumn{2}{|c|}{ Taquicardia } & & 93,34 \\
\hline & \multicolumn{2}{|c|}{ Bradicardia } & & 3,33 \\
\hline Desidratação & \multicolumn{2}{|c|}{ Presente } & & 95,38 \\
\hline Coloração de mucosa & \multicolumn{2}{|c|}{ Congesta } & & 84,13 \\
\hline Frequência respiratória & \multicolumn{2}{|c|}{ Taquipnéia } & & 83,87 \\
\hline Manifestação de dor & \multicolumn{3}{|c|}{$\begin{array}{l}\text { lo, gemidos, adota postura } \\
\text { antiálgica }\end{array}$} & 72,73 \\
\hline \multirow[t]{2}{*}{ Motilidade ruminal } & \multicolumn{3}{|c|}{ Hipomotílico } & 59,02 \\
\hline & \multicolumn{3}{|l|}{ Atonia } & 8,20 \\
\hline \multirow[t]{2}{*}{ Temperatura corpórea } & \multicolumn{3}{|c|}{ Hipertermia } & 53,45 \\
\hline & \multicolumn{3}{|c|}{ Hipotermia } & 1,72 \\
\hline Tensão abdominal & \multicolumn{3}{|c|}{ Aumentada } & 50 \\
\hline Comportamento & \multicolumn{3}{|c|}{ Apático } & 42,42 \\
\hline \multirow[t]{2}{*}{ Apetite } & \multicolumn{3}{|c|}{ Anorexia } & 30,30 \\
\hline & \multicolumn{3}{|c|}{ Hiporexia } & 7,58 \\
\hline $\begin{array}{l}\text { Alterações no trajeto pe- } \\
\text { niano }\end{array}$ & \multicolumn{3}{|l|}{ Edema } & 30,30 \\
\hline $\begin{array}{l}\text { Alterações de mucosa } \\
\text { prepucial }\end{array}$ & \multicolumn{3}{|c|}{ Prolapso } & 1,51 \\
\hline \multicolumn{5}{|c|}{$\begin{array}{l}\text { Quadro 3. Valores médios e desvios padrão dos achados } \\
\text { hematológicos e de bioquímica sérica de } 66 \text { ovinos com } \\
\text { quadro clínico de urolitíase obstrutiva,atendidos na CBG/ } \\
\text { UFRPE, durante os anos de } 2001 \text { a } 2008\end{array}$} \\
\hline Parâmetros & & Média & $\begin{array}{l}\text { Desvio } \\
\text { Padrão }\end{array}$ & $\begin{array}{l}\text { Valores } \\
\text { normais }\end{array}$ \\
\hline Hematócrito (\%) & & 34,25 & $\pm 5,44$ & $27-45^{*}$ \\
\hline Hemoglobina $(\mathrm{g} / \mathrm{dL})$ & & 11,39 & $\pm 1,98$ & $9-15^{*}$ \\
\hline Hemácias $\left(\mathrm{x} 10^{6} / \mathrm{mL}\right)$ & & 11,44 & $\pm 2,16$ & $9-15^{*}$ \\
\hline $\operatorname{VCM}(f \mathrm{~L})$ & & 30,26 & $\pm 2,98$ & $28-40^{*}$ \\
\hline CHCM (\%) & & 32,88 & $\pm 1,59$ & $31-34^{*}$ \\
\hline Leucócitos totai & & 11298,33 & $\pm 4116,82$ & $4-12^{*}$ \\
\hline Neutrófilos bas & $/ \mu \mathrm{L})$ & 326,86 & $\pm 386,96$ & Raros* \\
\hline Neutrófilos segmentados & $\mathrm{s}(/ \mu \mathrm{L})$ & 7476,35 & $\pm 519,41$ & $700-6000^{*}$ \\
\hline Eosinófilos $(/ \mu \mathrm{L})$ & & 215,39 & $\pm 224,75$ & $0-1000^{*}$ \\
\hline Basófilos $(/ \mu \mathrm{L})$ & & 276,25 & $\pm 232,73$ & $0-300^{*}$ \\
\hline Monócitos $(/ \mu \mathrm{L})$ & & 287,26 & $\pm 212,97$ & $0-750^{*}$ \\
\hline Linfócitos $(/ \mu \mathrm{L})$ & & 3444,12 & $\pm 1650,43$ & $2000-9000^{*}$ \\
\hline PPT (g/dL) & & 7,06 & $\pm 0,80$ & $6-7,5^{*}$ \\
\hline $\mathrm{FP}(\mathrm{mg} / \mathrm{dL})$ & & 544,07 & $\pm 221,49$ & $100-500^{*}$ \\
\hline Uréia $(\mathrm{mg} / \mathrm{dL})$ & & 185,61 & $\pm 176,06$ & $17,12-42,8^{* *}$ \\
\hline Creatinina $(\mathrm{mg} / \mathrm{dL})$ & & 4,71 & $\pm 4,75$ & $1,2-1,9^{* *}$ \\
\hline
\end{tabular}

*Byers \& Kramer(2010). ${ }^{* *}$ Kaneko et al. (2008).
Quadro 4. Principais achados físicos e químicos da urinálise de ovinos com quadro clínico de urolitíase obstrutiva,atendidos na CBG, durante os anos de 2001 e agosto de 2008

\begin{tabular}{lcc}
\hline Parâmetros & Achados & $\begin{array}{c}\text { Percentual de amostras } \\
\text { com alteração (\%) }\end{array}$ \\
\hline Odor & Sui generis & 100 \\
Cor & Normal & 78,57 \\
& Âmbar ou avermelhada & 21,43 \\
Aspecto & Turvo & 42,86 \\
Sangue & Presente & 89,29 \\
Proteína & Presente & 75 \\
pH & $5-6,5$ & 46,43 \\
Densidade & Abaixo da normalidade & 33,33 \\
Glicose & Presente & 7,14
\end{tabular}

Os demais parâmetros do exame químico da urina encontravam-se com valores dentro da normalidade para a espécie.

Quadro 5. Principais achados da sedimentoscopia urinária de ovinos com quadro clínico de urolitíase obstrutiva, atendidos na CBG, durante os anos de 2001 e 2008

\begin{tabular}{llr}
\hline \multicolumn{1}{c}{ Achados } & & $\begin{array}{r}\text { Percentual de a } \\
\text { com a alteraça }\end{array}$ \\
\hline Hemácias & & 77,78 \\
Células do epitélio uretral & 66,67 \\
Leucócitos & & 62,96 \\
Bactérias & & 22,22 \\
Células do epitélio renal & & 18,52 \\
Cristais & Urato amorfo & 51,85 \\
& Fosfato amorfo & 40,74 \\
& Carbonato de cálcio & 18,52 \\
& Fosfato triplo & 18,52 \\
& Fosfato de cálcio & 14,81 \\
& Oxalato de cálcio & 3,70 \\
& Ácido hipúrico & 3,70
\end{tabular}

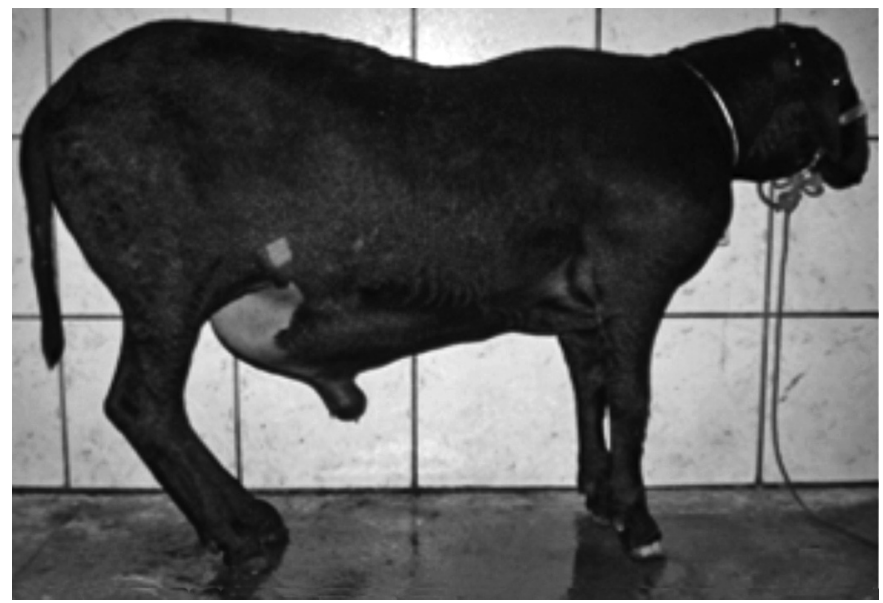

Fig.1. Ovino da raça Santa Inês apresentando edema prepucial e na região abdominal ventral.

$\mathrm{Na}$ necropsia, os achados macroscópicos renais mais frequentes foram pielonefrite $(61,54 \%)$ e hidronefrose $(50 \%)$, sendo também encontrados nefrite difusa, pielonefrite supurativa e urólitos (Fig.3A). Nos ureteres foram visualizados ureterite e hidroureter. Na bexiga foi mais evidente a cistite hemorrágica difusa $(50 \%)$ e a presença de urólitos $(57,69 \%)$ (Fig.3B), sendo também constatados alguns 


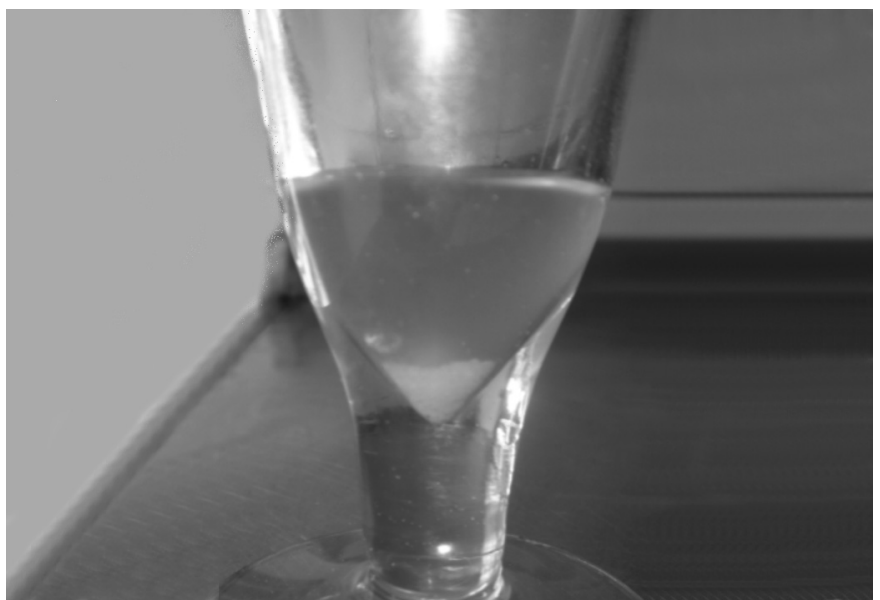

Fig.2. Urina apresentando aspecto turvo com urólitos sedimentados.
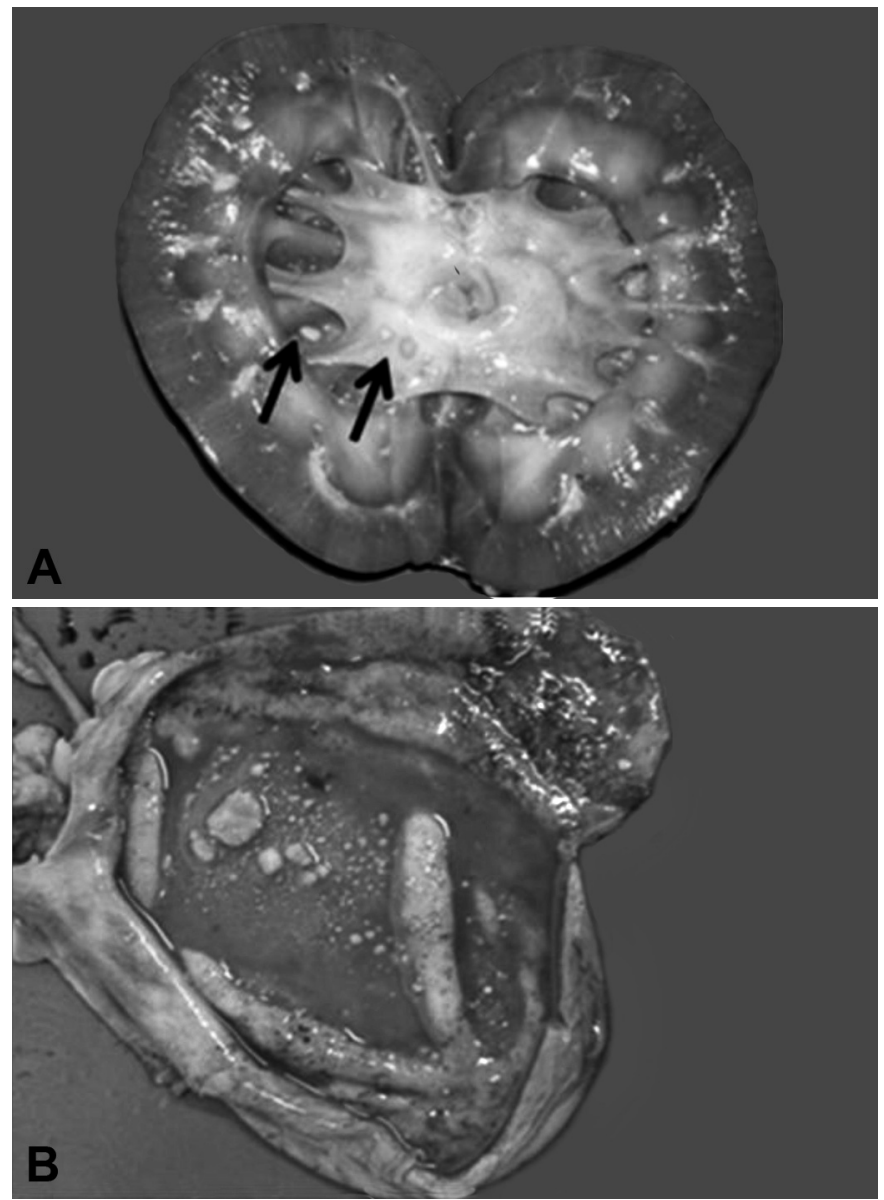

Fig.3. (A) Rim apresentando hidronefrose e urólitos (setas). (B) Bexiga apresentando cistite hemorrágica e presença de cálculos.

casos de cistite purulenta, presença de focos necróticos e ruptura vesical. Na uretra, a presença de urólitos $(61,54 \%)$ (Fig.4A) e a uretrite hemorrágica difusa $(57,69 \%)$ foram os achados de maior ocorrência, visualizando-se também uretrite purulenta e necrosante e poucos casos de ruptura.

O Quadro 6 mostra a composição dos urólitos de 18 ovinos estudados, sendo que $58,82 \%, 58,83 \%$ e $11,76 \%$ dos
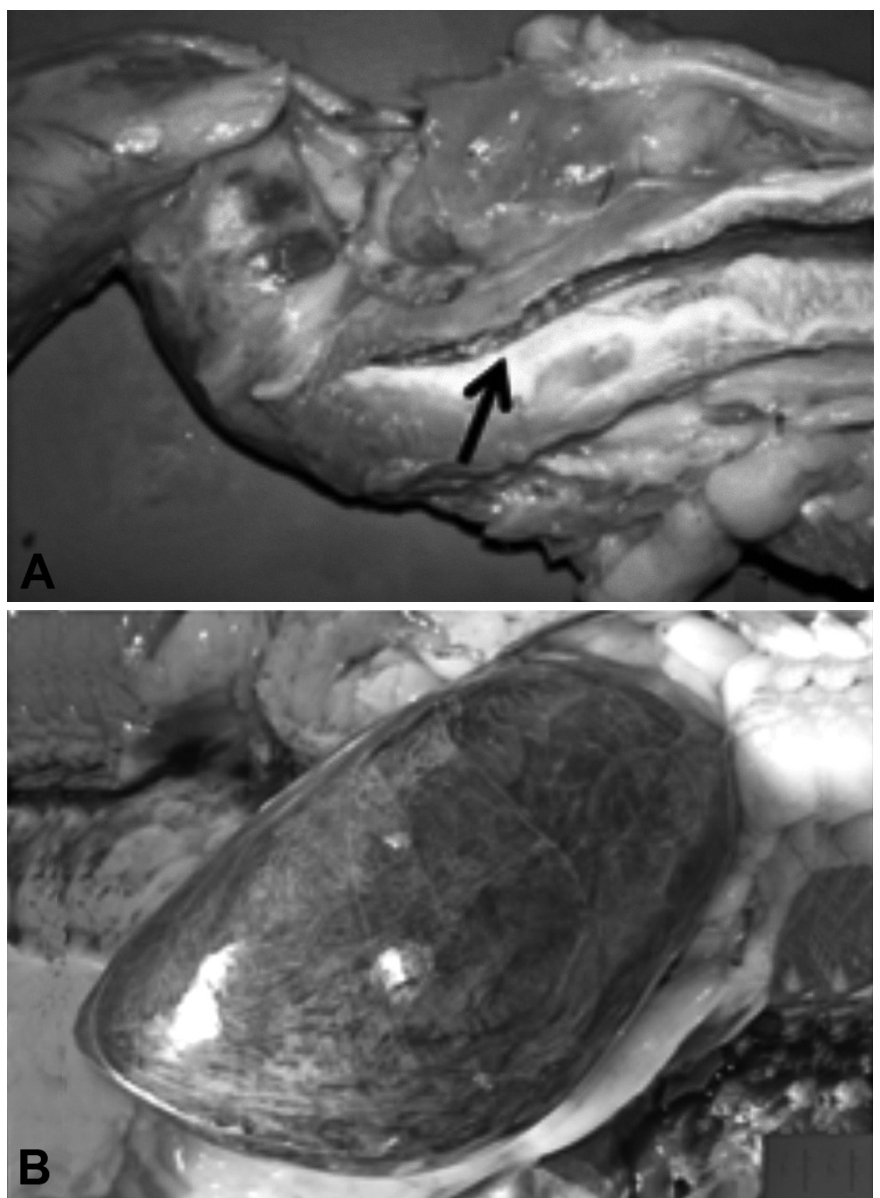

Fig.4. (A) Pênis apresentando cálculos uretrais (seta) na entrada da flexura sigmóide. (B) Bexiga urinária excessivamente distendida e com coloração vermelho escura.

Quadro 6. Composição dos urólitos coletados de 18ovinos com quadro de urolitíase obstrutiva, atendidos na CBG, no período de janeiro de 2000 a agosto de 2008

\begin{tabular}{lc}
\hline \multicolumn{1}{c}{ Constituição dos urólitos } & Percentual de a \\
\hline Oxalato de cálcio hidratado & 41,18 \\
Oxalato de sódio hidratado & 11,77 \\
Penicilina & 11,77 \\
Oxalato de cálcio & 5,88 \\
Carbonato de cálcio & 5,88 \\
Hidrocloreto & 5,88 \\
Metilfosfato de sódio & 5,88 \\
Fosfato de sódio e cálcio & 5,88 \\
Acetato hidroxílico & 5,88 \\
TOTAL & $100 \%$
\end{tabular}

cálculos possuíam cálcio, oxalato e fosfato em sua composição, respectivamente.

\section{DISCUSSÃO}

0 aumento da ocorrência da urolitíase obstrutiva se deve ao incremento verificado, nos últimos anos, do número de propriedades mais tecnificadas na região Nordeste e ao incentivo a produção de ovinos confinados, alimentados com concentrados, visando à comercialização em feiras e leilões (ARCO 2008). 
No período mais frio da região se concentrou o maior número de casos. A alimentação composta com alto teor de concentrado aliada a menor ingestão de água no período chuvoso são alguns dos fatores citados por Hay \& Suttle (1986) que diminuem o volume urinário, aumentam a concentração de solutos e favorecem a precipitação de sais na urina. Já para VinodhKumar et al. (2010), que trabalharam com ovinos criados na região semiárida da Índia, o período de maior ocorrência de urolitíase nos ovinos foi nos meses de verão, com $50,46 \%$ dos casos. Segundo os autores este comportamento deveu-se a redução na disponibilidade de água e da cobertura de forragem no solo nestes meses, o que levou os animais a ingerirem muita areia e pode ter induzido a um desequilíbrio da relação Ca:P.

Como pode ser observado, só foram registrados casos de urolitíase em machos. Bailey (1981) afirmou que processos obstrutivos ocorrem quase que exclusivamente em machos (99\%). Embora a formação de cálculo seja provavelmente igual em ambos os sexos, uma uretra mais curta e de maior diâmetro na fêmea oferece menores chances de obstrução. Apesar de raro, Gutierrez et al. (2000) descreveram o caso de uma cabra com disúria e oligúria, em virtude da presença de cálculos nos rins.

No que se refere à raça, Hay \& Suttle (1986), afirmam que o risco de urolitíase pode ser determinado, em parte, por variações raciais e por fatores intrínsecos de cada animal, estando relacionado a variações no metabolismo da água e na eficiência de absorção e retenção de minerais. De acordo com os mesmos autores os ovinos da raça Texel são particularmente eficientes na absorção e excreção de minerais, quando comparados com as raças Sulffok e Blackface, sendo mais predispostos a urolitíase devido a elevada concentração de minerais na urina. Neste trabalho a maior ocorrência em ovinos Santa Inês e Dorper deve-se, provavelmente, ao fato de que estas raças predominam nas criações do nordeste (Lôbo 2005).

Mais da metade dos animais apresentavam idade inferior a um ano. Este fato pode estar relacionado ao desenvolvimento incompleto da uretra no animal jovem somado a superalimentação a que os animais eram submetidos objetivando a preparação e/ou manutenção da fase reprodutiva e apresentações em feiras e leilões. McIntosh et al. (1974) também afirmaram que a urolitíase constitui importante causa de perdas de animais, principalmente na faixa etária inferior a seis meses. Este comportamento também foi observado por VinodhKumar et al. (2010) que registraram taxa de ocorrência de 52,29\% em cordeiros desmamados. Já Pugh (2004) registrou esta ocorrência em animais castrados e atribui este achado ao menor desenvolvimento da uretra, decorrente da falta de estímulos hormonais. Porém, tal observação não foi verificada neste estudo, tendo em vista que todos os animais eram machos não castrados. Este achado, provavelmente está relacionado ao fato de que a suplementação alimentar com concentrados em grande quantidade é oferecida, preferencialmente, a animais reprodutores ou que serão comercializados para reprodução.

A alimentação rica em concentrados e o manejo intensivo predominaram neste estudo, o que corrobora os achados de Riet-Correa et al. (2008) ao descreverem casos de urolitíase em ovinos e caprinos. Esta alimentação está relacionada à formação de cálculos devido ao fato de possuírem níveis de fósforo superiores aos de cálcio, o que leva a proporção de cálcio/fósforo da dieta a níveis de 1:1 ou menores acarretando fosfatemia e formação de cálculos com alto percentual de fósforo (Tiruneh 2006, Riet-Correa et al. 2008). No entanto, nossos resultados corroboram os resultados de Trueman \& Stacy (1969) e Osborne et al. (1989), que observaram predominância de sais de cálcio nos urólitos de ovinos. Este achado pode ser explicado pela dieta acidogênica que pode desenvolver um estado de acidose metabólica crônica (Owens et al. 1998). Segundo Takagi \& Block (1991) o estado de acidose metabólica estimula a transformação de 25(OH) colicalciferol em 1,25 dihidroxicolicalciferol, o qual aumenta a reabsorção óssea liberando cálcio para a corrente sanguínea, aumentando assim a excreção urinária do mesmo. Fato bem relatado por Del Claro et al. (2006), que trabalhando com ovinos da raça Santa Inês, demonstraram que a utilização de dieta acidogênica, obtida pela redução do balanço cátion-aniônico aumentou significativamente a excreção de cálcio pela urina.

Sobre a presença de oxalato nos cálculos, Van Metre \& Divers (2006) explicam que forragens com elevado teor de cálcio e baixo teor de fósforo e magnésio possuem alto teor de oxalatos, o que aumenta a excreção desse elemento na urina. Quanto aos urólitos formados por penicilina supõe-se que o uso indiscriminado deste fármaco seja a causa de sua presença, uma vez que sua excreção é por via urinária $\mathrm{Hu}$ ber 1992). Como constatado, o cálcio $(58,82 \%)$ e o oxalato $(58,83 \%)$ foram os principais componentes dos urólitos analisados, o que corrobora os achados de Tiruneh (2000), ao estudar tal enfermidade em bovinos de corte na Etiópia.

Os primeiros sinais de urolitíase geralmente são anorexia e meteorismo, o que pode confundir o clínico no momento da primeira observação (Riet-Correa et al. 2008). 0 meteorismo não foi observado nesta avaliação; pelo contrário, todos os animais que ingressaram na CBG já apresentavam sinais evidentes de obstrução urinária, o que confirma a demora no atendimento e o aumento da gravidade dos sinais, corroborando os achados de Tiruneh (2000). VinodhKumar et al. (2010) observaram anorexia, depressão e em alguns casos agitação na fase inicial e distensão abdominal bilateral e ranger de dentes após iniciados os primeiros sintomas.

Segundo Ortolani (1996), a manifestação de dor abdominal advém da síndrome cólica devido à dificuldade de micção. 0 estímulo da dor age diretamente no centro gástrico, levando a anorexia e depressão da motilidade dos pré-estômagos, justificando a presença de animais com apetite e motilidade ruminal diminuídos ou ausentes. A febre, taquicardia e taquipnéia também podem estar relacionadas à dor, pois esta desencadeia a liberação de prostaglandina, adrenalina e noradrenalina que são mediadores destes processos (Van Metre \& Divers 2006, Radostits et al. 2007). Soma-se a isto a reação inflamatória provocada pela ação irritativa dos cálculos nos tecidos. Esta pode ser agravada por uma infecção bacteriana secundária (Confer \& Panciera 1998) e desencadear a liberação dos mediadores da inflamação (Van Metre \& Divers 2006). 
A desidratação verificada na quase totalidade dos animais acometidos foi relatada por Donecker \& Bellamy (1982), que a justifica por estar relacionada à ruptura de bexiga e consequente sequestro de líquido para cavidade. No entanto, nos ovinos acompanhados foram observados poucos casos de ruptura de bexiga, estando este achado, provavelmente relacionado à baixa ingestão de água pelos animais. 0 edema e o prolapso de mucosa prepucial observados (Fig.1) estão relacionados à ruptura de uretra ou extravasamento de urina para o tecido subcutâneo devido à distensão uretral excessiva (Radostits et al. 2007). A congestão de mucosas aparentes está relacionada à uremia decorrente da estase urinária (Confer \& Panciera 1998).

As alterações encontradas no leucograma e fibrinogênio plasmático estão de acordo com Pugh (2004) e Van Metre \& Divers (2006), que relatam serem estes achados freqüentes nos casos de infecção renal aguda, cistite e uretrite. VinodhKumar et al. (2010) também observaram linfocitopenia e hemoconcentração. 0 quadro de azotemia pós-renal encontrado está relacionado à estase urinária e consequente reabsorção destes compostos (Coelho 2002, Van Metre \& Divers 2006, Fettman \& Rebar 2007).

Nos achados da urinálise, a hematúria esteve presente em mais de $80 \%$ dos casos, provavelmente em decorrência das lesões hemorrágicas provocadas pela presença de cálculos na mucosa do trato urinário (Confer \& Panciera 1998). Este achado foi descrito com frequência em casos de obstrução parcial da uretra (Pugh 2004, Radostits et al. 2007, Riet-Correa 2007, Riet-Correa et al. 2008, VinodhKumar et al. 2010). 0 aspecto turvo da urina deve-se a elevada contagem celular urinária, representada pelo aumento do número de células epiteliais, eritrócitos, leucócitos, bactérias, muco ou cristais (Garcia-Navarro 1996, Hendrix 2006). Quanto à proteinúria presente na maioria das amostras, esta é justificada nos casos de glomerulonefrite, nefrite intersticial, pielonefrite ou nefrose, em que a proteína atravessa a membrana glomerular e apenas as de baixo peso molecular são reabsorvidas, o restante aparece na urina, como proteinúria grave (Garcia-Navarro 1996). Todavia, inflamações no trato urogenital, hemoglobinúria e hematúria podem influenciar no teste, dando um resultado de proteína positivo, devido à existência nelas de exsudatos protéicos (Dirksen et al. 1993, Garcia-Navarro 1996, Pugh 2004). Desta forma, os resultados encontrados podem ter sido influenciados por este fator, uma vez que a contagem de leucócitos e hemácias do sedimento urinário estava elevada na maioria das análises.

De acordo com Confer \& Panciera (1998), a expressão principal de doença glomerular é o extravasamento de proteínas para o filtrado glomerular e para a urina, enquanto que a presença de glicosúria indica lesão tubular. Tendo em vista que as dosagens de glicose encontravam-se dentro da normalidade e que a proteinúria pode ter sido influenciada pela presença maciça de leucócitos e hemácias, supõe-se que a função de filtração renal, da maioria dos animais no primeiro momento, ainda não havia sido comprometida, pois segundo Van Metre \& Divers (2006), para que haja insuficiência renal é necessário que aproximadamente $75 \%$ dos néfrons de ambos os rins sejam perdidos, provocando inadequada excreção de uréia e creatinina, proteinúria, glicosúria e aumento da celularidade do sedimento urinário. Embora as dosagens de uréia e creatinina tenham atingido valores elevados, este fato está relacionado à estase urinária e consequente reabsorção destes compostos o que caracteriza uma azotemia pós-renal e não propriamente uma insuficiência renal (Coelho 2002).

Com relação ao alto índice de animais com acidúria, este tem relação com a alimentação, em função da ingestão de grande quantidade de grãos que provoca a queda do pH (Garcia-Navarro 1996, Van Metre \& Divers 2006). Estes resultados diferem dos descritos por VinodhKumar et al. (2010) que constataram pH urinário entre 8,0 e 8,2 em animais com urolitíase.

A densidade urinária diminuída em uma pequena parcela de indivíduos pode estar relacionada a lesões renais como nefrite aguda ou pielonefrite, já que a diminuição da capacidade de concentração urinária é consequência frequente de danos renais (Garcia-Navarro 1996). A grande quantidade de hemácias e leucócitos na sedimentoscopia pode representar alterações inflamatórias, supurativas ou necrose em qualquer ponto do aparelho urogenital (Garcia-Navarro 1996, Meseguer \& Yagüe 2003).

Segundo Garcia-Navarro (1996), a presença de células do epitélio uretral, renal e bactérias na sedimentoscopia devem ser analisadas com cautela, pois nas infecções urinárias o número de bactérias está aumentado e sua interpretação deve sempre estar associada ao número de leucócitos. 0 mesmo se diz das células do epitélio uretral, que quando estão aumentadas no sedimento urinário indicam inflamação e irritação. Já as células epiteliais renais normalmente estão ausentes na urina e sua presença indica um processo de descamação tubular.

Quanto a presença dos cristais, Meseguer \& Yagüe (2003) afirmam que dependem do $\mathrm{pH}$, da solubilidade e da concentração dos cristalóides, geralmente, trata-se de um achado inespecífico e raramente tem valor diagnóstico. No entanto, quando se refere à urolitíase, o achado de cristais pode ajudar na identificação da natureza mineral dos cálculos (Garcia-Navarro 1996). Contudo, este fato não foi aqui verificado.

Quanto à letalidade, esta foi expressivamente maior entre os animais que apresentavam obstrução total da uretra. Achado corroborado por Donecker \& Bellamy (1982), que relataram um índice de letalidade de 50,8\% em bovinos com obstrução total da uretra e 10,5\% em bovinos com obstrução parcial. Bruère \& West (1993) afirmaram que a severidade dos sinais clínicos pode variar dependendo da localização da obstrução e se esta é completa ou parcial.

Os achados necroscópicos são semelhantes aos descritos por diversos autores (Van Metre \& Divers 2006, Radostits et al. 2007, Riet-Correa 2007, Riet-Correa et al. 2008, VinodhKumar et al. 2010). De acordo com Confer \& Panciera (1998), os cálculos podem ser encontrados na pelve renal, no ureter ou em qualquer porção do trato urinário inferior. Quando localizados neste último ponto, causam a retenção de urina na bexiga, o que leva à cistite, juntamente com a lesão da mucosa mediante a ação física dos cálculos. 
A cistite, de acordo com Hay \& Suttle (1986), é comumente hemorrágica e acompanhada por urólitos e uretrite, como observada no presente estudo. Tais alterações predispõem a pielite, pielonefrite e hidronefrose, devido ao refluxo vesicoureteral que ocorre quando há aumento da pressão dentro da bexiga, como observado na obstrução uretral (Confer \& Panciera 1998, Coelho 2002).

A presença de peritonite ou celulite subcutânea são sequelas da saída de urina para fora do trato urinário, tanto por ruptura da bexiga ou uretra, quanto por extravasamento em virtude da pressão na luz uretral provocada pela estase urinária (Hay \& Suttle1986, Radostits et al. 2007).

Em conclusão, a urolitíase obstrutiva é uma enfermidade de fácil diagnóstico, porém de difícil tratamento, uma vez que pode deixar sequelas locais ou sistêmicas, ou levar o animal à morte. 0 tipo de sistema de criação associado ao alto percentual de concentrado na ração total, a ingestão de forragens com altos níveis de oxalato e a baixa ingestão de água podem ser os principais fatores para ocorrência de tal enfermidade. A análise de composição dos cálculos urinários mostra o envolvimento do metabolismo hormonal e mineral na enfermidade, o que precisa ser mais estudado. A prevenção, por meio do sistema de criação e dietas adequadas para cada ambiente e faixa etária dos machos ovinos, parece ser a melhor alternativa no controle da urolitíase obstrutiva.

\section{REFERÊNCIAS}

ARCO 2008. Santa Inês conquista novos mercados. Ano 2, no 3, fevereiro/ março. Disponível em <http://www.arcoovinos.com.br/jornal_fev2008. pdf.> Acesso 18 jan. 2009.

Bailey C.B. 1981. Silica metabolism and silica urolithiasis: A review. Can. J. Anim. Sci.61(2):219-235.

Betejtin A. 1977. Curso de Mineralogia. 3aㅡ ed. Mir Publishers, Moscou. 739p.

Bruère A.N. \& West D.M. 1993. The sheep: Health, disease and production. Continuing Education, New Zeland. 397p.

Byers S.R. \& Kramer J.W. 2010. Normal hematology of sheep and goats, p.836-842. In: Weiss D.J. \& Wardrop K.J. (Eds), Schalm's Veterinary Hematology. 6 ed. Blackwell, Iowa.

Coelho H.E. 2002. Patologia Veterinária. Editora Manole, São Paulo. 234p.

Confer A.W. \& Panciera R.J. 1998. Sistema urinário, p.228-260. In: Carlton W.W. \& McGavin M.D. (Eds), Patologia Veterinária Especial de Thomson. $2^{\underline{a}}$ ed. Artmed, Porto Alegre.

Del Claro G.R., Zanetti M.A., Correa L.B., Saran Neto A., Paiva F.A. \& Salles M.S.V. 2006. Balanço cátion-aniônico da dieta no metabolismo de cálcio em ovinos. Ciência Rural 36(1):222-228.

Dirksen G., Gründer H.D. \& Stöber M. 1993. Rosenberger, Exame Clínico dos Bovinos. $3^{\mathrm{a}}$ ed. Guanabara Koogan, Rio de Janeiro. 419p.

Donecker J.M. \& Bellamy J.E.C. 1982. Blood abnormalities in cattle with ruptured bladders and urethras. Can. Vet. J. 23:355-357.

Fettman M.J. \& Rebar A. 2007. Avaliação da função renal, p.285-310. In: Thrall M.A. (Ed.), Hematologia e Bioquímica Veterinária. Roca, São Paulo.

Garcia-Navarro C.E.K. 1996. Manual de urinálise veterinária. Livraria Varela, São Paulo. 95p.
Gutierrez C., Escolar E., Juste M.C., Palacios M.P. \& Corbera J.A. 2000. Severe urolithiasis due to trimagnesium orthophosphate calculi in a goat. Vet. Rec. 146:534.

Hay L.A. \& Suttle N.F. 1986. Urolithiasis, p.250-253. In: Jensen R. (Ed.), Diseases of Sheep. Blackwell Scientific Publications, Oxford.

Hendrix C.M. 2006. Urinálise, p.227-268. In: Hendrix C.M. (Ed.), Procedimentos laboratoriais para técnicos veterinários. $4^{\mathrm{a}}$ ed. Roca, São Paulo.

Huber W.G. 1992. Penicilinas, p.642-654. In: Booth N.H. \& McDonald L.E. (Eds), Farmacologia e Terapêutica em Veterinária. 5a ed. Guanabara Koogan, Rio de Janeiro.

Jain N.C. 1986. Schalm's Veterinary Hematology. 4aㅡ ed. Lea and Febiger, Philadelphia. 1221p.

Kaneko J.J., Harvey J.W. \& Bruss M.L. 2008. Clinical Biochemistry of Domestic Animals. 6 ed. Academic Press, New York. 916p.

Lôbo R.N.B. 2005. Sistema de produção de caprinos e ovinos de corte para o nordeste brasileiro: raças. Sistemas de Produção, Embrapa Caprinos, Sobral. Versão Eletrônica. Disponível em <http://sistemasdeproducao. cnptia.embrapa.br/fonteshtml/caprinoseovinosdecorte/caprinoovinoscortenebrasil> Acesso em 18 jan. 2009.

McIntosh G.H., Pulsford M.F., Spencer W.G. \& Rosser H. 1974. A study of urolithiasis in grazing ruminants in south Australia. Aust. Vet. J. 50:345350.

Melendez P., Rae O. \& Risco C. 2007. Urinary bladder rupture, urolithiasis, and azotemia in a Brangus Bull: a herd approach. Bov. Pract. 41(2):121128.

Meseguer J.P. \& Yagüe L.M.C. 2003. Biopatología clínica renal. Bovis 111:71-81.

Ortolani E.L. 1996. Intoxicação e doenças metabólicas em ovinos: intoxicação cúprica, urolitíase e toxemia da prenhez, p.241-258. In: Sobrinho A.G.S., Batista A.M.V., Siqueira E.R., Ortolani E.L., Susin I., Silva J.F.C., Teixeira J.C. \& Borba M.F.S. (Eds), Nutrição de Ovinos. Funep, Jaboticabal.

Osborne C.A., Sanna J.J., Unger L.K., Clinton C.W. \& Davenport M.P. 1989. Analyzing the mineral composition of uroliths from dogs, cats, horses, cattle, sheep, goats, and pigs. Vet. Med. 84:750-764.

Owens F.N., Secrist D.S., Hill W.J. \& Gill D.R. 1998. Acidosis in cattle: A review. J. Anim. Sci. 75(3):727-735.

Pugh D.G. 2004. Clínica de Ovinos e Caprinos. Roca, São Paulo. 513p.

Radostits O.M., Gay C.C., Hinchcliff K.W. \& Constable P.D. 2007. Veterinary Medicine: A textbook of the diseases of cattle, horses, sheep, pigs and goats. $10^{\text {th }}$ ed. Saunders, Edinbourg. 2156p.

Riet-Correa F. 2007. Outras doenças, p.623-684. In: Riet-Correa F., Schild A.L., Lemos R.A.A. \& Borges J.R. (Eds), Doenças de Ruminantes e Eqüídeos. 3a ed. Pallotti, Santa Maria.

Riet-Correa F., Simões S.D.V. \& Vasconcelos J.S. 2008. Urolitíase em caprinos e ovinos. Pesq. Vet. Bras. 28(6):319-322.

Takagi H. \& Block E. 1991. Effects of manipulating dietary cation-anion balance on macromineral balance in sheep. J. Dairy Sci. 74(12):4202-4214.

Tiruneh R.A. 2000. Retrospective study on ruminant urethral obstruction in Debre Zeitárea, Ethiopia. Revue Méd. Vét. 151(8/9):855-860.

Tiruneh R.A. 2006. Ruminant urolithiasis in Ethiopia: Alterations of mineral concentrations in bovine urine and sheep sera according to the geographic origin or the diet regimen. Revue Méd. Vét.157(5):261-164.

Trueman N.A. \& Stacy B.D. 1969. Ovine urolithiasis: some mineralogic and physiologic observations. Investigative Urology 4(2):185-191.

Van Metre D.C. \& Divers T.J. 2006. Urolitíase, p.853-860.In: Smith B.P. (Ed.), Medicina Interna de Grandes Animais. 2ª ed. Manole, São Paulo.

VinodhKumar O.R., Swarnkar C.P., Shinde A.K. \& Singh D. 2010. Clinical, mineral and haemato-biochemical studies of urolithiasis in wearner lambs. Afr. J. Agric. Res. 5(15):2045-2050. 